\title{
Product formulation is crucial to the success of lipid- based bio-fungicides
}

\author{
Kirstin Wurms* and Annette Ah Chee \\ The New Zealand Institute for Plant \& Food Research Limited, Ruakura, Private Bag 3230, \\ Hamilton 3240, New Zealand \\ * Corresponding author: kirstin.wurms@plantandfood.co.nz
}

\begin{abstract}
Powdery mildew is a major cause of damage to squash plants. Anhydrous milk fat (AMF) or soybean oil (SBO) may be effective at treating this disease but these active ingredients must be mixed with an emulsifier to enable even distribution and suspension of fat globules, and an antioxidant to prevent rancidity. The overall formulation may affect disease control efficacy, leaf health and product stability. The effect of different emulsifiers and antioxidants on emulsion stability, odour and shelf-life of AMF and SBO bio-fungicides was tested in laboratory assays, and on powdery mildew disease control efficacy and leaf health on glasshouse-grown squash plants. Both AMF and SBO formulations including a polyglycerol ester emulsifier (Grindsted ${ }^{\oplus}$ PGE 20 Veg) resulted in the best emulsion stability, disease control and leaf health. None of the antioxidants tested significantly affected on disease control efficacy in AMF formulations, but $\mathrm{SBO}$ formulations containing vitamin $\mathrm{E}$ as the antioxidant provided the best disease control efficacy and emulsion stability.
\end{abstract}

Keywords anhydrous milk fat, antioxidant, bio-fungicide, emulsifier, formulation, powdery mildew, soybean oil.

\section{INTRODUCTION}

Various pathogens in the order Erysiphales cause a disease known as powdery mildew (PM) on a range of crops, including Cucurbita maxima (squash), and are responsible for significant yield losses globally. Powdery mildew of squash is a major problem for commercial growers in New Zealand. Synthetic chemical fungicides, known as demethylation inhibitors, have been used to control these fungi for many years. However, the fungi have developed resistance to these fungicides so there is a demand for newgeneration fungicides. There is also demand for environmentally-friendly treatments, and biofungicides (fungicides comprising biological control agents and/or natural products) are one option that can provide durable control in both conventional and organic systems.

Anhydrous milk fat (AMF) and soybean oil (SBO) formulations have been identified in field and glasshouse trials as natural, environmentallybenign bio-fungicides for control of PM and other pathogens, with efficacy rivalling that of synthetic pesticides currently on the market (Ah Chee et al. 2011; Wurms et al. 2011; Wurms \& Ah Chee 2011; Wurms \& Hofland-Zijlstra 2015). The three main components of these bio-fungicide formulations are: (i) the lipid active ingredient; (ii) an emulsifier that prevents the lipids from separating out from the water diluent; and (iii) an antioxidant, which minimises the breakdown of the fatty acid chains and associated development of rancid odours (Wurms \& Ah Chee 2007). Careful selection of all three components is important to maximise the performance of the formulation in terms of disease control efficacy, emulsion stability, product shelf life, ease of use, cost and odour. Lipid bio-fungicide formulations must be efficacious without causing phytotoxicity, because fats and oils are often associated with 
chlorosis and necrosis of plant tissue (Finger et al. 2002; Moran et al. 2003; Baysal-Gurel \& Miller 2015; Zhuang et al. 2015). Moreover, individual components, which act a certain way when used singly, may perform quite differently in the presence of other compounds. Optimisation of product formulation is, therefore, an essential part of the pathway to develop commercially acceptable bio-fungicides. Ah Chee et al. (2018) (the preceding paper in this volume) identified two promising candidate active ingredients (AMF and SBO). The study reported here evaluated these bio-fungicides in term of: the performance of different chemical families of emulsifiers and antioxidants on emulsion stability; odour and shelf-life in laboratory assays; and on powdery mildew disease control efficacy and phytotoxicity on glasshouse-grown squash plants. The emulsifiers and antioxidants were selected on the basis of their physical properties, such as their ability to emulsify fats, their generally-regardedas-safe (GRAS) environmental status, and via recommendations of people skilled in the art of lipid formulation within the food industry (Andrea McDonald, Danisco New Zealand Limited; Sandra Murray, Hawkins Watts Limited New Zealand; Derek Horne, Dupont New Zealand; and John Lloyd, Axis Associates New Zealand, personal communications).

\section{MATERIALS AND METHODS}

\section{Trial 1 - AMF}

The concentration of each of the ingredients tested was determined in unpublished preliminary trial work and consisted of fat (AMF) $7 \mathrm{~g} / \mathrm{L}$, emulsifier; $4 \mathrm{~g} / \mathrm{L}$ and antioxidant $1 \mathrm{~g} / \mathrm{L}$. The amount of AMF was lower than those examined by Ah Chee et al. (2018) because lower concentrations were shown to be conducive to better plant health without adversely affecting efficacy (Wurms, unpublished data). These concentrations were suitable for use as a 'ready-to-use' spray. Panodan ${ }^{\circledR} \mathrm{AL} 10$ (Danisco Ltd, Braband, Denmark) is a diacetyl tartaric acid ester of mono- and diglycerides (DATEM) and was used as the emulsifier in all the antioxidant comparisons, as it had been used in previous experimental work. Grindox ${ }^{\mathrm{Tm}} 122$
(Danisco Ltd) is a mixture of propyl gallate and a citric acid monoglyceride ester and was used as the antioxidant in all the emulsifier comparisons because it was a beneficial addition to the formulations tested by Ah Chee et al. (2018).

One litre of twenty-fold concentrate was prepared of each of the nine different biofungicide formulations shown in Table 1 (Treatments (Trt) 2-10). Details of the chemicals used are provided in Table 1. The emulsifiers were from the following chemical families: diacetyl tartaric acid esters of mono- and diglycerides (DATEM, Trt 2, 8, 9, 10); citric acid ester of mono-glyceride (Citrem, Trt 3); polyglycerol esters (PGE, Trt 4); polyglycerol polyricinoleate (PGPR, Trt 5); phosphoric acid ester (lecithin, Trt 6); and a mixture of calcium and sodium stearoyl lactylate (SSL,CSL, Trt 7). Antioxidant chemical families were: propyl gallate (122, Trts 2-7); ascorbal palmitate (AP, Trt 8); mixed tocopherols (vitamin E) (T70, Trt 9); and tertiary butylhydroquinone (204, Trt 10).

The concentrated AMF formulations were stored at room temperature and diluted with water ( $50 \mathrm{~mL}$ of $20 \mathrm{x}$ concentrate $+950 \mathrm{~mL}$ water) to produce field rates, before spray application in the glasshouse trial. A dilution series $(50 \mathrm{x}$, $35 \mathrm{x}, 30 \mathrm{x}, 25 \mathrm{x}, 20 \mathrm{x}, 15 \mathrm{x}, 10 \mathrm{x}, 5 \mathrm{x}$ and $1 \mathrm{x}$ the field rate) of each AMF formulation was assessed for $\mathrm{pH}$, stability and odour on the day they were produced. Only the results from the 20 -fold concentrate are presented, as this proved to be the most stable concentrate for all the different formulation ingredients. The $\mathrm{pH}$ was measured using Merck $\mathrm{pH}$ indicator strips - a broad range strip ( $\mathrm{pH} 0-14$ ) was used in the first instance, and then a narrower range strip (usually covering $4 \mathrm{pH}$ units) to gain a more accurate measurement of $\mathrm{pH}$. Stability was assessed as the time taken for the emulsion to separate into phases after agitation. The arbitrary scale used to describe odour was: $0=$ no smell; $1=$ faint odour, barely detectable; $2=$ mild smell, but pleasant; $3=$ moderate smell; $4=$ strong smell, but not too offensive; $5=$ strong offensive smell.

The formulated concentrates were also assessed for the time the product could be stored 
Table 1 Composition of the anhydrous milk fat (AMF) formulations and other treatments used in the laboratory and in glasshouse trial 1.

\begin{tabular}{|c|c|c|}
\hline Treatment (Trt) \# & Trt abbreviation $^{1}$ & Trt details (ready-to-spray concentration) \\
\hline 1 & Water & Inoculated control - water \\
\hline 2 & AMF/DATEM/122 & $\operatorname{AMF}(7 \mathrm{~g} / \mathrm{L})+\operatorname{DATEM}(4 \mathrm{~g} / \mathrm{L})+122(1 \mathrm{~g} / \mathrm{L})$ \\
\hline 3 & AMF/Citrem/122 & $\operatorname{AMF}(7 \mathrm{~g} / \mathrm{L})+\operatorname{Citrem}(4 \mathrm{~g} / \mathrm{L})+122(1 \mathrm{~g} / \mathrm{L})$ \\
\hline 4 & AMF/PGE/122 & $\operatorname{AMF}(7 \mathrm{~g} / \mathrm{L})+\operatorname{PGE}(4 \mathrm{~g} / \mathrm{L})+122(1 \mathrm{~g} / \mathrm{L})$ \\
\hline 5 & AMF/PGPR/122 & $\operatorname{AMF}(7 \mathrm{~g} / \mathrm{L})+\operatorname{PGPR}(4 \mathrm{~g} / \mathrm{L})+122(1 \mathrm{~g} / \mathrm{L})$ \\
\hline 6 & AMF/Lecithin/122 & $\operatorname{AMF}(7 \mathrm{~g} / \mathrm{L})+$ lecithin $(4 \mathrm{~g} / \mathrm{L})+122(1 \mathrm{~g} / \mathrm{L})$ \\
\hline 7 & AMF/SSL,CSL/122 & $\operatorname{AMF}(7 \mathrm{~g} / \mathrm{L})+\mathrm{SSL}, \mathrm{CSL}(4 \mathrm{~g} / \mathrm{L})+122(1 \mathrm{~g} / \mathrm{L})$ \\
\hline 8 & AMF/DATEM/AP & $\operatorname{AMF}(7 \mathrm{~g} / \mathrm{L})+\operatorname{DATEM}(4 \mathrm{~g} / \mathrm{L})+\operatorname{AP}(1 \mathrm{~g} / \mathrm{L})$ \\
\hline 9 & AMF/DATEM/T70 & $\operatorname{AMF}(7 \mathrm{~g} / \mathrm{L})+\operatorname{DATEM}(4 \mathrm{~g} / \mathrm{L})+\mathrm{T} 70(1 \mathrm{~g} / \mathrm{L})$ \\
\hline 10 & AMF/DATEM/204 & $\operatorname{AMF}(7 \mathrm{~g} / \mathrm{L})+\operatorname{DATEM}(4 \mathrm{~g} / \mathrm{L})+204(1 \mathrm{~g} / \mathrm{L})$ \\
\hline
\end{tabular}

${ }^{1}$ Treatment codes are given in the order AMF/emulsifier/antioxidant, and the abbreviations correspond to the

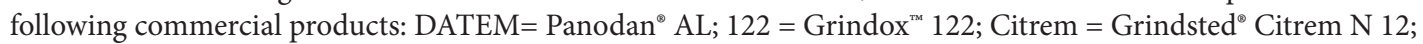
PGE $=$ Grindsted $^{\star}$ PGE 20 Veg; PGPR $=$ Grindsted ${ }^{\circ}$ PGPR; Lecithin $=$ Lecithin granules; SSL,CSL $=$ Grindsted ${ }^{\star}$ SSL $/$ CSL P; AP $=$ Grindox $^{\text {mex }}$ AP kosher; T70 $=$ Guardian $^{\text {mm }}$ Toco 70; $204=$ Grindox $^{\text {mex }} 204$. All emulsifiers and antioxidants were sourced from Danisco NZ Limited, except for lecithin, which came from Hawkins Watts NZ Limited. AMF was obtained from New Zealand Milk Products Limited.

without chemical and physical destabilisation, i.e. shelf life. Change in the chemical structure over time is most commonly associated with lipid oxidation. Before a bio-fungicide can obtain registration, it needs to undergo shelf-life testing using protocols specified by the ACVM (Agricultural Compounds and Veterinary Medicines) group (Ministry for Primary Industries 2018). At the time that this research was initiated, product stored for 2 weeks at $54^{\circ} \mathrm{C}$ was thought to simulate a 2 -year shelf life at ambient temperature (New Zealand Food Safety Authority 2006). Consequently, triplicate $50-\mathrm{mL}$ samples of the concentrate of each formulation were stored for 2 weeks in a $54^{\circ} \mathrm{C}$ oven and then reassessed for $\mathrm{pH}$, stability and odour.

Squash (Cucurbita maxima) 'Delica' seedlings were potted in an $80 \%$ bark : $20 \%$ pumice mix and maintained in glasshouses, with temperatures ranging from $15^{\circ} \mathrm{C}$ (night) to $25^{\circ} \mathrm{C}$ (day), and a natural photo-period and daily watering. Plants were trained up taut strings suspended from the glasshouse roof. Flowers, fruit and secondary shoots were removed throughout the course of the trial, as were growing tips once the plants had reached an adequate size (11+ true leaves). The trial was set up using a complete randomised block design (RBD), with five replicate plants per treatment and one replicate (rep) of each treatment per block. All treatments were prepared the day before application and stored overnight at $4^{\circ} \mathrm{C}$. Treatment applications (Table 1) were at 7 -day intervals and involved spraying all leaves to run-off (approximately $5 \mathrm{~mL}$ per leaf) using hand-held mister-bottles. Six spray applications were made in total, with approximately $1 \%$ of the leaf area naturally infected with PM at the time of the first treatment application.

Disease severity on true leaves 1-8 was rated fortnightly using percent leaf area infection diagrams and a disease rating scale (Table 2) described by Spencer (1977). 
Qualitative assessments of leaf health were made simultaneously using an arbitrary 7-point scale (Table 3).

Table 2 Powdery mildew leaf disease rating scale from Spencer (1977).

\begin{tabular}{cc}
\hline Rating & Leaf area (\%) infected \\
\hline 0 & no infection \\
1 & $0-1$ \\
2 & $2-5$ \\
3 & $6-20$ \\
4 & $21-40$ \\
5 & $>40$ \\
6 & 100 \\
\hline
\end{tabular}

\section{Trial 2 - SBO with emulsifiers}

Preliminary experiments (data not shown here) established that ready-to-use spray concentrations of each of the ingredients tested were SBO 5 $\mathrm{g} / \mathrm{L}$, emulsifier $1.33 \mathrm{~g} / \mathrm{L}$ and antioxidant 0.33 g/L. SBO (AMCO brand) was purchased from the supermarket. In the time elapsed between the AMF and SBO glasshouse experiments, Grindox $^{\text {tm }} 122$ was taken off the market and hence it was replaced with the next best performing antioxidant still on the market (T70). One litre of twenty-fold concentrate was prepared of each of six different soybean emulsions as shown in Table 4 (Trts 3-8).

Concentrated soybean emulsions tested for $\mathrm{pH}$, stability, and odour both on the day of production, and after 2 -weeks' storage at $54^{\circ} \mathrm{C}$, as described previously. Concentrates were stored at room temperature prior to use and were diluted on the day of use before spray application in the glasshouse trial.

Squash (Cucurbita maxima) 'Delica' seedlings were raised as described in the AMF experiment, except that plants were staked instead of being trained up strings. The trial was set up using a complete RBD, with six replicate plants per treatment and one rep/treatment/block. Plants were artificially inoculated with inoculum of the cucurbit PM pathogen Sphaerotheca fuliginea sourced from a commercial grower of glasshouse cucumbers. Populations of this obligate pathogen were maintained on inoculum plants in a separate growing area. Infected leaves from inoculum plants were inverted spore-side down onto the first (basal) true leaf of each squash plant used in the experiment. The rest of the leaves were left to develop infection naturally. Artificial inoculation was used to ensure that infection was present before the commencement of the trial, as PMinfected cucurbits had not been grown in this particular glasshouse previously.

The eight treatments (Table 4) were applied on a weekly basis for five weeks, commencing two weeks following inoculation when there was $\leq 5 \%$ PM infection on leaves 5-10. Application involved spraying all leaves to run-off using hand-held mister bottles. Disease severity (Table 2) was assessed weekly, one day before each spray application, on true leaves 5-10. Qualitative assessments of leaf health/condition were also carried out (Table 3 ).

Table 3 Arbitrary scale used to describe the condition of leaves infected with powdery mildew.

\begin{tabular}{cl}
\hline Leaf-health rating & \multicolumn{1}{c}{ Leaf physical characteristics } \\
\hline A & Perfect condition - no abiotic or biotic blemishes \\
B & Minor imperfections, not exceeding a $5 \mathrm{~mm}^{2}$ area \\
C & Small blemishes $5-10 \mathrm{~mm}^{2}$, e.g. chlorotic spots, rubbing \\
D & Necrotic/chlorotic patches (coalesced spots), leaf distortion \\
E & Severe/advanced chlorosis, necrosis or leaf distortion \\
F & More than $20 \%$ of the leaf area is dead \\
G & Leaf dead \\
\hline
\end{tabular}


Table 4 Composition of the soybean oil (SBO) formulations with different emulsifiers and other treatments used in the laboratory and glasshouse trial 2.

\begin{tabular}{|c|c|c|}
\hline Treatment (Trt) \# & Trt abbreviation $^{1}$ & Trt details (ready-to-spray concentration) \\
\hline 1 & Water & Inoculated control - water \\
\hline 2 & Kumulus & Fungicide control - Kumulus ${ }^{\circledast}$ DF (3 g/L) \\
\hline 3 & $\mathrm{SBO} / \mathrm{PGE} / \mathrm{T} 70$ & SBO $(5 \mathrm{~g} / \mathrm{L})+\operatorname{PGE}(1.33 \mathrm{~g} / \mathrm{L})+\mathrm{T} 70(0.33 \mathrm{~g} / \mathrm{L})$ \\
\hline 4 & SBO/DATEM/T70 & $\operatorname{SBO}(5 \mathrm{~g} / \mathrm{L})+\operatorname{DATEM}(1.33 \mathrm{~g} / \mathrm{L})+\mathrm{T} 70(0.33 \mathrm{~g} / \mathrm{L})$ \\
\hline 5 & SBO/Citrem/T70 & $\mathrm{SBO}(5 \mathrm{~g} / \mathrm{L})+$ Citrem $(1.33 \mathrm{~g} / \mathrm{L})+\mathrm{T} 70(0.33 \mathrm{~g} / \mathrm{L})$ \\
\hline 6 & SBO/PGPR/T70 & SBO $(5 \mathrm{~g} / \mathrm{L})+$ PGPR $(1.33 \mathrm{~g} / \mathrm{L})+\mathrm{T} 70(0.33 \mathrm{~g} / \mathrm{L})$ \\
\hline 7 & SBO/SSL,CSL/T70 & $\operatorname{SBO}(5 \mathrm{~g} / \mathrm{L})+\operatorname{SSLCSL}(1.33 \mathrm{~g} / \mathrm{L})+\mathrm{T} 70(0.33 \mathrm{~g} / \mathrm{L})$ \\
\hline 8 & SBO/Lecithin/T70 & SBO $(5 \mathrm{~g} / \mathrm{L})+$ lecithin $(1.33 \mathrm{~g} / \mathrm{L})+\mathrm{T} 70(0.33 \mathrm{~g} / \mathrm{L})$ \\
\hline
\end{tabular}

${ }^{1}$ Treatment code abbreviations are the same as in Table 1.

\section{Trial 3 - SBO with antioxidants}

Ready-to-use spray concentrations were the same as in the SBO emulsifier trial, except for SBO/PGE/half T70 where the amount of T70 was halved from $0.33 \mathrm{~g} / \mathrm{L}$ to $0.17 \mathrm{~g} / \mathrm{L}$ (Table 5). T70 was the most expensive ingredient used so a lower rate that was still active would be more cost effective. One litre of twenty-fold concentrate was prepared of each of the formulations (Table 5). Concentrated soybean emulsions were stored at room temperature and tested for $\mathrm{pH}$, stability, and odour both on the day of production, and after 2-weeks' storage at $54^{\circ} \mathrm{C}$ for the best performing antioxidants. Three replicate batches of Trts 3 and 4 (Table 5) were also analysed for free fatty acids by AsureQuality Limited (Auckland, NZ) using the method of Perrin \& Perrin (1958). The amounts of free fatty acids increase as complex lipids are degraded, so the values provide a quantitative indication of the extent of lipid oxidation. Concentrates were diluted on the day of use before spray application in the glasshouse trial. The same polyglycerol ester emulsifier (Grindsted ${ }^{\oplus}$ PGE 20 Veg) was used in treatments 3-10. An equivalent polyglycerol ester emulsifier (Palsgaard ${ }^{\circledR}$ PGE 117) from another manufacturer was used in treatment 11 to test for differences between products.

The squash 'Delica' seedlings were raised as described previously. The trial was set up using a complete RBD, with seven replicate plants per treatment and one treatment replicate per block. Artificial inoculation of the first true leaf was carried out to ensure that low-level infection was present across all plants at commencement of the trials. Treatments (Table 5) were applied on a weekly basis for 6 weeks, commencing four days after artificial inoculation, when there was $\leq 5 \%$ PM infection. Disease severity and leaf health were assessed weekly, one day before each spray application, on true leaves 2-10.

\section{Statistical analyses}

Disease severity scores on the final assessment were averaged for each plant and were converted into quantitative percent infection values by taking the mid-point of the infection range corresponding to each severity score. Treatment differences were analysed using a RBD by analysis of variance (ANOVA), with means separation by Fisher's Least Significant Difference $(\mathrm{P}<0.05)$, using Genstat 17th Edition. Qualitative assessments such as the leaf health ratings were not statistically analysed.

\section{RESULTS}

AMF trials

Citrem and PGE were the most stable emulsifiers (Table 6), while formulations containing DATEM emulsifier were always more acidic and had a stronger odour than other formulations. Antioxidants had no effect on stability, but $\mathrm{pH}$ 
Table 5 Composition of the soybean oil (SBO) formulations with different antioxidants and other treatments used in the laboratory and glasshouse trial 3.

\begin{tabular}{|c|c|c|}
\hline Treatment (Trt) \# & Trt abbreviation $^{1}$ & Trt details (ready-to-spray concentration) \\
\hline 1 & Water & Inoculated control - water (negative control) \\
\hline 2 & Kumulus & $\begin{array}{l}\text { Fungicide control - Kumulus }{ }^{\circledR} \text { DF }(3 \mathrm{~g} / \mathrm{L}) \text { (positive } \\
\text { control) }\end{array}$ \\
\hline 3 & $\mathrm{SBO} / \mathrm{PGE} / \mathrm{T} 70 \mathrm{std}$ & SBO $(5 \mathrm{~g} / \mathrm{L})+$ PGE $(1.33 \mathrm{~g} / \mathrm{L})+\mathrm{T} 70(0.33 \mathrm{~g} / \mathrm{L})$ \\
\hline 4 & $\mathrm{SBO} / \mathrm{PGE} /$ half T70 & $\mathrm{SBO}(5 \mathrm{~g} / \mathrm{L})+\mathrm{PGE}(1.33 \mathrm{~g} / \mathrm{L})+\mathrm{T} 70(0.17 \mathrm{~g} / \mathrm{L})$ \\
\hline 5 & SBO/PGE/T50 & $\mathrm{SBO}(5 \mathrm{~g} / \mathrm{L})+\mathrm{PGE}(1.33 \mathrm{~g} / \mathrm{L})+\mathrm{T} 50(0.33 \mathrm{~g} / \mathrm{L})$ \\
\hline 6 & $\mathrm{SBO} / \mathrm{PGE} / \mathrm{AP}$ & $\mathrm{SBO}(5 \mathrm{~g} / \mathrm{L})+\mathrm{PGE}(1.33 \mathrm{~g} / \mathrm{L})+\mathrm{AP}(0.33 \mathrm{~g} / \mathrm{L})$ \\
\hline 7 & $\mathrm{SBO} / \mathrm{PGE} / 204$ & $\mathrm{SBO}(5 \mathrm{~g} / \mathrm{L})+\mathrm{PGE}(1.33 \mathrm{~g} / \mathrm{L})+204(0.33 \mathrm{~g} / \mathrm{L})$ \\
\hline 8 & $\mathrm{SBO} / \mathrm{PGE} / 106$ & $\mathrm{SBO}(5 \mathrm{~g} / \mathrm{L})+\mathrm{PGE}(1.33 \mathrm{~g} / \mathrm{L})+106(0.33 \mathrm{~g} / \mathrm{L})$ \\
\hline 9 & SBO/PGE/MTS-70 & $\operatorname{SBO}(5 \mathrm{~g} / \mathrm{L})+\operatorname{PGE}(1.33 \mathrm{~g} / \mathrm{L})+\operatorname{MTS} 70(0.33 \mathrm{~g} / \mathrm{L})$ \\
\hline 10 & SBO/PGE/E700D & $\mathrm{SBO}(5 \mathrm{~g} / \mathrm{L})+\operatorname{PGE}(1.33 \mathrm{~g} / \mathrm{L})+\operatorname{E} 700 \mathrm{D}(0.33 \mathrm{~g} / \mathrm{L})$ \\
\hline 11 & SBO/Alt PGE/T70 & $\operatorname{SBO}(5 \mathrm{~g} / \mathrm{L})+$ Alt PGE $(1.33 \mathrm{~g} / \mathrm{L})+\mathrm{T} 70(0.33 \mathrm{~g} / \mathrm{L})$ \\
\hline
\end{tabular}

${ }^{1}$ Treatment code abbreviations are the same as in Table 1. In addition, $106=$ Grindox $^{\mathrm{tm}} 106$ antioxidant; MTS70 $=$ Decanox $^{\text {tm }}$ MTS70 Mixed Tocopherols antioxidant; E700D = Novatol ${ }^{\text {Tw }}$ E700D Vitamin E antioxidant; Alt PGE = Palsgaard ${ }^{\circ}$ PGE 117 emulsifier. 106 is supplied by Danisco New Zealand Limited via Du Pont Nutrition and Health, and the last three compounds come from Hawkins Watts New Zealand.

decreased and odour increased in all formulations following 2-weeks' storage at $54^{\circ} \mathrm{C}$ (Table 6).

Addition of an emulsifier to the formulation had a significant effect on PM disease control efficacy, but addition of an antioxidant did not, Figure 1. The best disease control was obtained using the emulsifiers DATEM, PGE or SSL,CSL. There was no significant difference in PM infection among any of the different antioxidant treatments, and water-treated plants were significantly more infected than all other treatments (Fig. 1).

The different AMF formulations had some beneficial effect on the health of infected leaves with AMF/PGE/122 and AMF/SSL,CSL/122 being the most beneficial (leaf-health rating C), followed by AMF/Citrem/122 and AMF/ DATEM/AP (rating D) whilst all other treatments had a rating of E, except for the water control where leaves were dead (rating G) as a result of being overwhelmed by damage associated with heavy PM infestation.

\section{SBO emulsifier trials}

Only the SBO/PGE/T70, SBO/Citrem/T70 and SBO/SSL,CSL/T70 emulsions were stable before storage (Table 7), with all other emulsions separating into oil and water phases immediately after shaking. SBO/Citrem/T70, SBO/SSL,CSL/ T70 and SBO/Lecithin/T70 also had flocculation evident clinging to the sides of the Schott bottles (images not shown). All treatments were tested on the plants, irrespective of stability.

Stability of SBO/SSL,CSL/T70 was destroyed in the accelerated storage test at $54^{\circ} \mathrm{C}$, resulting in a cottage cheese-like consistency. The $\mathrm{pH}$ decreased and odour increased after storage to a greater or lesser degree in most of the emulsions after accelerated storage (Table 7).

Glasshouse trial results showed that $\mathrm{SBO} /$ Citrem/T70 and SBO/SSL,CSL/T70 provided poor disease control, whereas all the other soybean emulsions provided disease control as good as that provided by the Kumulus ${ }^{\otimes}$ fungicide (Fig. 2).

Kumulus was the most beneficial treatment (leaf-health rating C), followed by SBO/DATEM/ 
Table 6 Assessments of $\mathrm{pH}$, stability and odour of nine anhydrous milk fat (AMF) formulation concentrates (20x field application rate) before and after 2-weeks' storage at $54^{\circ} \mathrm{C}$.

\begin{tabular}{|c|c|c|c|c|c|c|c|}
\hline \multirow{2}{*}{$\begin{array}{l}\text { Trt } \\
\#\end{array}$} & \multirow{2}{*}{ Trt abbreviation } & \multicolumn{3}{|c|}{ Before storage } & \multicolumn{3}{|c|}{ After storage } \\
\hline & & Stability $^{1}$ & $\mathrm{pH}$ & Odour $^{2}$ & Stability & $\mathrm{pH}$ & Odour $^{2}$ \\
\hline 2 & AMF/DATEM/122 3 & $\begin{array}{l}2 \text { phases } \\
\text { after } 1 \mathrm{~h}\end{array}$ & 2.3 & 3.5 & $\begin{array}{l}2 \text { phases } \\
\text { after } 2 \text { min }\end{array}$ & 2.0 & 4.0 \\
\hline 3 & AMF/Citrem/122 & stable $^{4}$ & 4.8 & 1.0 & Stable & 4.0 & 1.2 \\
\hline 4 & $\mathrm{AMF} / \mathrm{PGE} / 122$ & stable $^{4}$ & 4.6 & 0.7 & $\begin{array}{l}2 \text { phases } \\
\text { after } 15 \mathrm{~min}\end{array}$ & 3.4 & 1.0 \\
\hline 5 & AMF/PGPR/122 & $\begin{array}{l}2 \text { phases } \\
\text { after } 1 \mathrm{~h}\end{array}$ & 4.6 & 0.7 & $\begin{array}{l}2 \text { phases } \\
\text { after } 30 \mathrm{~min}\end{array}$ & 3.5 & 1.0 \\
\hline 6 & AMF/Lecithin/122 & 2 phases $^{5}$ & 4.5 & 1.0 & $\begin{array}{l}2 \text { phases } \\
\text { after } 2 \text { min }\end{array}$ & 3.8 & 1.5 \\
\hline 7 & AMF/SSL,CSL/122 & 2 phases $^{5}$ & 4.6 & 1.0 & 2-3 phases & 3.6 & 1.5 \\
\hline 8 & AMF/DATEM/AP & $\begin{array}{l}2 \text { phases } \\
\text { after } 1 \mathrm{~h}\end{array}$ & 2.4 & 2.5 & 2 phases & 1.9 & 3.0 \\
\hline 9 & AMF/DATEM/T70 & stable & 2.5 & 3.5 & 2 phases & 2.0 & 4.0 \\
\hline 10 & AMF/DATEM/204 & $\begin{array}{l}2 \text { phases } \\
\text { after } 1 \mathrm{~h}\end{array}$ & 2.3 & 2.0 & 2 phases & 2.0 & 3.0 \\
\hline
\end{tabular}

${ }^{1}$ Stability was assessed as the time taken for the emulsion to separate into phases after agitation.

${ }^{2}$ Odour was assessed using the following arbitrary scale: $0=$ no smell; $1=$ faint odour, barely detectable; $2=$ mild smell, but pleasant enough; $3=$ moderate smell; $4=$ strong smell, but not too offensive; $5=$ strong offensive smell. Values provided are the averages from 2-3 assessors.

${ }^{3}$ Treatment code abbreviations are the same as in Table 1.

${ }^{4}$ Emulsions that did not separate into phases after more than three days are listed as "stable".

${ }^{5}$ For emulsions that separated into phases immediately (i.e. $0 \mathrm{~s}$ after shaking), only the number of phases is given.

T70 (rating D), then SBO/PGE/T70, SBO/PGPR/ T70 and SBO/Lecithin/T70 (rating E). Treatments SBO/Citrem/T70 and SBO, SSL, CSL/T70 were ineffective in protecting against PM (rating F), while leaves in the water treatment were dead (rating G) as a result of being overwhelmed by damage associated with heavy PM infestation.

\section{SBO antioxidant trials}

The SBO/PGE/204 and SBO/PGE/106 emulsions were not stable before storage (Table 8), with separation into oil and water phases occurring 15-30 s after shaking. The SBO/PGE/AP emulsion also had flocculation evident clinging to the sides of the Schott bottle. All other emulsions were stable before storage (Table 8 ). The $\mathrm{pH}$ decreased after storage to a greater or lesser degree in most of the emulsions after accelerated storage, but odour was largely unaffected (Table 8).

Both SBO/PGE/T70 std and SBO/PGE/half
T70 had the same pre-storage free fatty acid value of $0.043 \pm 0$ (mean \pm standard error), which increased during accelerated storage to $0.053 \pm$ 0.003 for SBO/PGE/T70 std and $0.050 \pm 0.003$ for $\mathrm{SBO} / \mathrm{PGE} /$ half T70.

Soybean emulsions were less effective than Kumulus fungicide, but still significantly reduced disease relative to the water control (Fig. 3). The treatments SBO/PGE/204 and SBO/ $\mathrm{PGE} / 106$ provided significantly greater disease control than the two poorest treatments, $\mathrm{SBO} /$ PGE/MTS-70 and SBO/PGE/E700D (Fig. 3). Halving the amount of T70 antioxidant, or using a different source of PGE emulsifier, did not significantly affect disease control (Fig. 3). Percent leaf infection in the water control, which is indicative of disease pressure, was higher in the SBO antioxidant trial (Fig. 3) than in the SBO emulsifier trial (Fig. 2). 


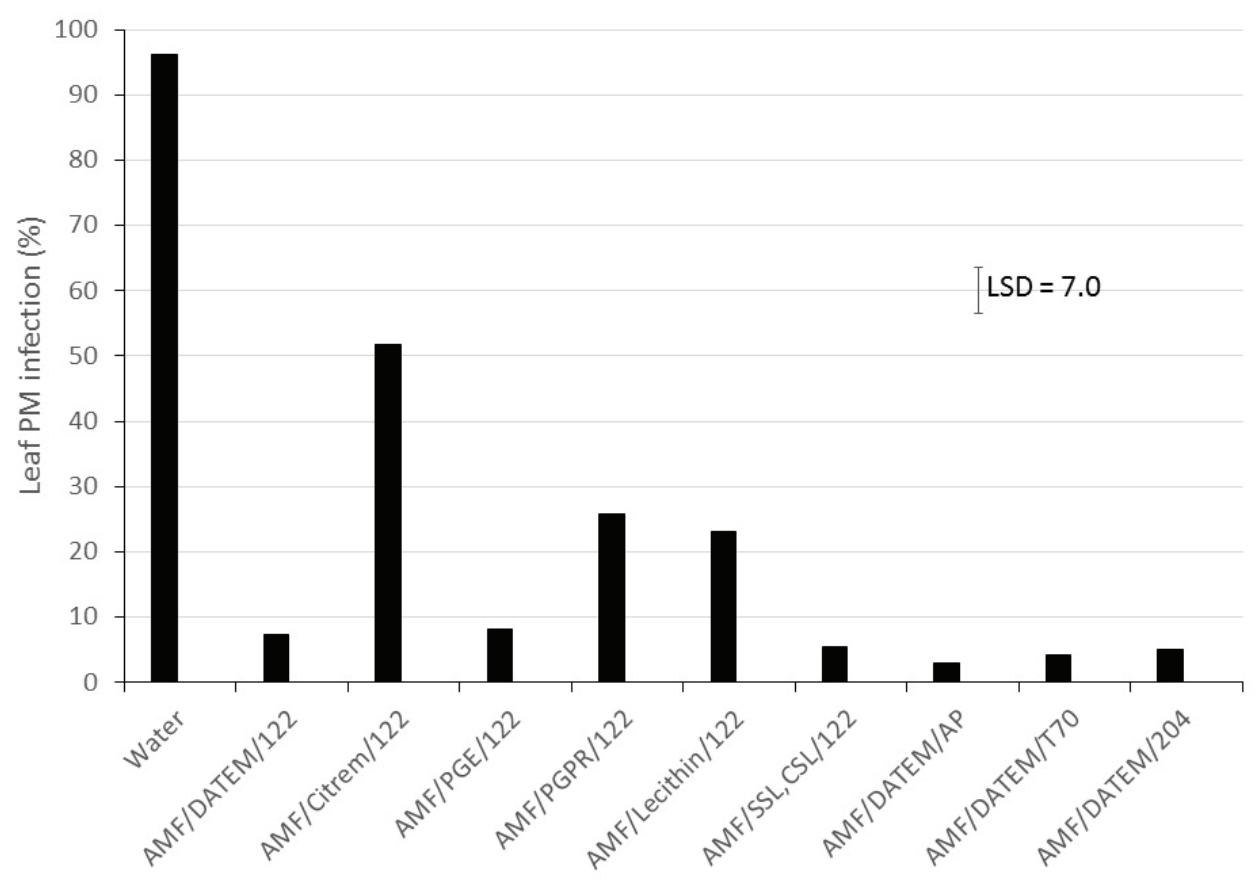

Figure 1 Percentage of powdery mildew (PM) infection on 'Delica' squash leaves, after six weekly spray applications of various anhydrous milk fat (AMF) emulsions. Treatment codes are given in the order AMF/emulsifier/antioxidant, and the abbreviations correspond to the following commercial products: DATEM $=$ Panodan $^{\oplus}$ AL; $122=$ Grindox $^{\text {mix }} 122$; Citrem $=$ Grindsted $^{\oplus}$ Citrem N 12; PGE $=$ Grindsted $^{\oplus}$ PGE 20 Veg; PGPR= Grindsted ${ }^{\circledR}$ PGPR; Lecithin = Lecithin granules SSL,CSL= Grindsted ${ }^{\oplus}$ SSL $/$ CSL P; AP $=$ Grindox $^{\text {tm }}$ AP kosher; T70 $=$ Guardian $^{\text {ma }}$ Toco 70; $204=$ Grindox $^{\text {me }} 204$. Data were analysed by analysis of variance (ANOVA), with means separation by Fisher's Least Significant Difference (LSD) $(\mathrm{P}<0.05)$.

Table 7 Assessments of $\mathrm{pH}$, stability and odour of six soybean oil (SBO) formulation concentrates before and after 2-weeks' storage at $54^{\circ} \mathrm{C}$.

\begin{tabular}{clcccccc}
\hline \multirow{2}{*}{$\begin{array}{c}\text { Trt } \\
\#\end{array}$} & \multirow{2}{*}{ Trt abbreviation } & \multicolumn{2}{c}{ Before storage } & \multicolumn{3}{c}{ After storage } \\
& & Stability & $\mathrm{pH}$ & Odour $^{2}$ & Stability & $\mathrm{pH}$ & Odour \\
\hline 3 & SBO/PGE/T70 & stable & 6.1 & 2.0 & stable & 6.1 & 3.0 \\
4 & SBO/DATEM/T70 & 2 phases & 2.0 & 4.5 & 3 phases & 2.0 & 4.3 \\
5 & SBO/Citrem/T70 & stable & 5.0 & 1.0 & stable & 4.0 & 2.2 \\
6 & SBO/PGPR & 2 phases & 5.8 & 3.0 & 2 phases & 5.3 & 3.2 \\
7 & SBO/SSL,CSL/T70 & stable & 6.0 & 2.0 & $2-3$ phases & 4.5 & 3.0 \\
8 & SBO/Lecithin/T70 & 2 phases & 5.1 & 1.0 & 3 phases & 5.0 & 3.0 \\
\hline
\end{tabular}

${ }^{1}$ Stability assessed as described in Table 6.

${ }^{2}$ Odour assessed as described in Table 6.

${ }^{3}$ Treatment code abbreviations are the same as in Table 1. 


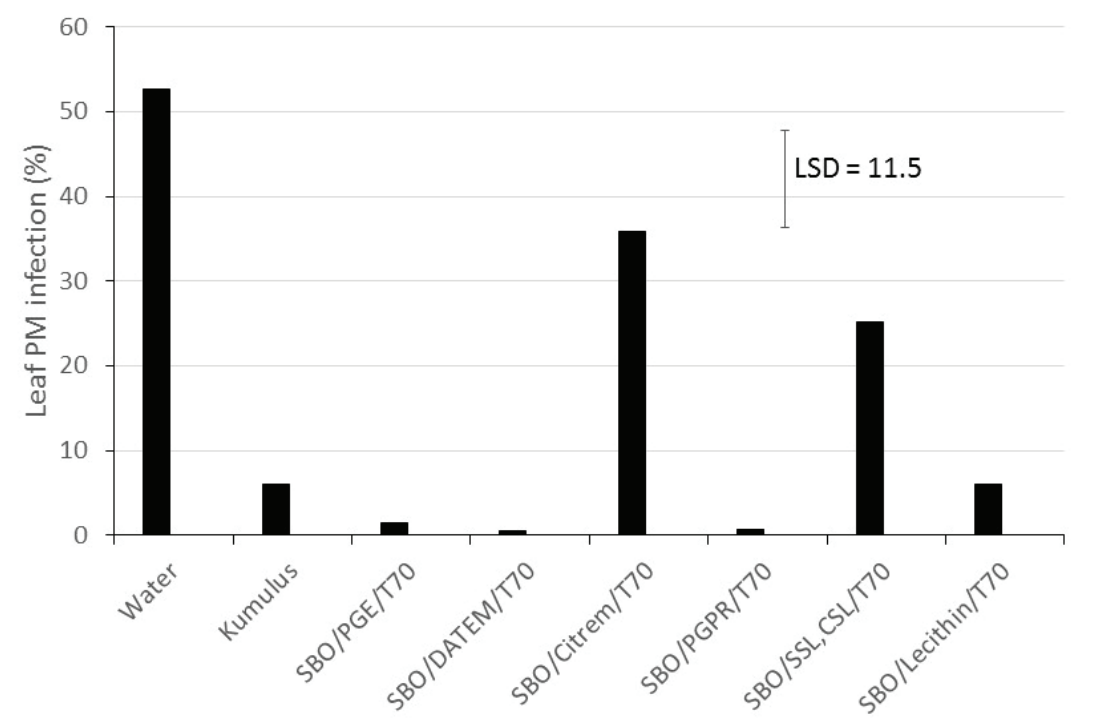

Figure 2 Percentage of powdery mildew (PM) infection on 'Delica' squash leaves, assessed 5 weeks after artificial inoculation of the first true leaf, and weekly spray applications of various soybean oil (SBO) emulsions, with treatment abbreviations being the same as in Figure 1, with the addition of Kumulus = Kumulus ${ }^{\circledast}$ fungicide. Data were analysed by ANOVA, with means separation by LSD $(\mathrm{P}<0.05)$.

Table 8 Assessments of $\mathrm{pH}$, stability and odour of soybean oil (SBO) formulation concentrates before and after 2-weeks' storage at $54^{\circ} \mathrm{C}$.

\begin{tabular}{|c|c|c|c|c|c|c|}
\hline \multirow{2}{*}{ Trt abbreviation } & \multicolumn{3}{|c|}{ Before storage } & \multicolumn{3}{|c|}{ After storage } \\
\hline & Stability $^{1}$ & $\mathrm{pH}$ & Odour $^{2}$ & Stability & $\mathrm{pH}$ & Odour \\
\hline $\mathrm{SBO} / \mathrm{PGE} / \mathrm{T} 70^{3} \mathrm{std}$ & stable & 8.9 & 2 & stable & 8.4 & 2.0 \\
\hline SBO/PGE/half T70 & stable & 9.0 & 2 & stable & 8.0 & 2.0 \\
\hline SBO/PGE/T50 & stable & 8.8 & 1 & -4 & - & - \\
\hline SBO/PGE/AP & $\begin{array}{l}\text { stable, but } \\
\text { flocculation }\end{array}$ & 6.4 & 2.5 & - & - & - \\
\hline SBO/PGE/204 & $\begin{array}{l}3 \text { phases } \\
\text { after } 30 \mathrm{~s}\end{array}$ & 3.6 & 2 & $\begin{array}{l}3 \text { phases } \\
\text { after } 30 \mathrm{~s}\end{array}$ & 3.5 & 1.0 \\
\hline SBO/PGE/106 & $\begin{array}{l}2 \text { phases } \\
\text { after } 15 \mathrm{~s}\end{array}$ & 4.0 & 1 & $\begin{array}{l}2 \text { phases } \\
\text { after } 15 \mathrm{~s}\end{array}$ & 3.5 & 1.0 \\
\hline SBO/PGE/MTS-70 & stable & 9.2 & 2 & - & - & - \\
\hline SBO/PGE/E700D & stable & 8.9 & 2 & - & - & - \\
\hline SBO/Alt PGE/T70 & stable & 8.1 & 1 & stable & 6.9 & 1.0 \\
\hline
\end{tabular}

${ }^{1}$ Stability assessed as described in Table 6.

${ }^{2}$ Odour assessed as described in Table 6.

${ }^{3}$ Treatment abbreviations are the same as in Table 5.

${ }^{4}$ Not measured - accelerated storage trials were only performed on treatments with best PM disease control efficacy. 
Treatment of infected leaves with Kumulus resulted in the best leaf health (ranking $\mathrm{C}$ ). The use of water resulted in a leaf-health ranking of $\mathrm{F}$, while the mean leaf health rating for all other treatments was $\mathrm{E}$.

Overall, results obtained for the performance tests of the different formulations carried out in the laboratory were the same regardless of whether the active ingredient was AMF or SBO. The most stable emulsions both before and after storage were those containing PGE and Citrem emulsifiers. Formulations containing Grindox $^{\mathrm{mm}} 204$ or Grindox ${ }^{\mathrm{Tm}} 106$ as the antioxidant were unstable and the AP antioxidant was associated with flocculation. The two PGE emulsifiers tested gave identical results. The active ingredient in a formulation is the most important factor in its disease-control efficacy but the choice of emulsifier choice (but not antioxidant) was also shown to have a significant effect (Figs. 1-3). Citrem, PGPR and lecithin emulsifiers resulted in less effective disease control with the AMF active ingredient while formulations containing Citrem and SSL,CSL resulted in poorer disease control in the SBO experiment.

\section{DISCUSSION}

The results obtained here show that formulations containing a combination of fatty acid, emulsifier and antioxidant can be effective in preventing the spread of powdery mildew on squash leaves. A range of emulsifiers and antioxidants representative of different chemical families were tested for emulsion stability, odour and shelf-life in laboratory assays, and for PM disease control efficacy and leaf health on glasshouse-grown squash plants. The type of emulsifier affected the stability and efficacy of formulations with

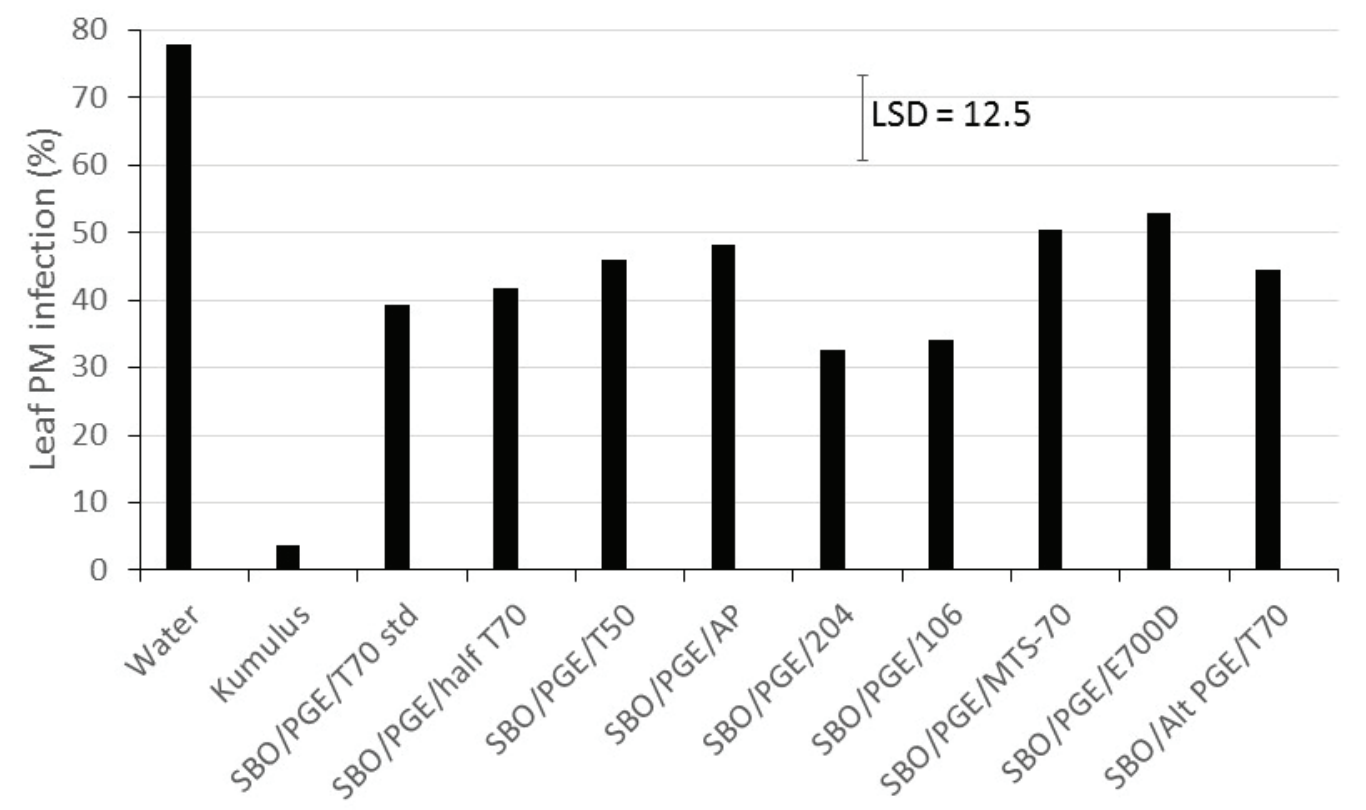

Figure 3 Percentage of powdery mildew (PM) infection on 'Delica' squash leaves, assessed 4 weeks after artificial inoculation of the first true leaf, and weekly spray applications of various soybean emulsions. Treatment abbreviations are the same as in Figure 1, with the addition of $106=$ Grindox $^{\mathrm{mm}} 106$ antioxidant; MTS70 $=$ Decanox $^{\mathrm{mm}}$ MTS70 Mixed Tocopherols antioxidant; E700D $=$ Novatol $^{\mathrm{mm}}$ E700D Vitamin E antioxidant; Alt PGE $=$ Palsgaard ${ }^{\circledR}$ PGE 117 emulsifier. ANOVA was performed on the data, with means separation by LSD $(\mathrm{P}<0.05)$. 
the same type and amount of active ingredient. Antioxidant choice affected stability but not efficacy.

Unstable emulsions are undesirable because separation of the emulsion into phases will allow larger amounts of oil to come into direct contact with the plant surface. Moreover, separation into phases means that the lipid component will not adequately be protected against fatty acid oxidation during long-term storage, which may lead to irreversible chemical changes in the product. Unstable emulsions can also cause blockage of spray equipment, although this did not appear to be the case in the glasshouse trials conducted here. The $\mathrm{pH}$ either remained relatively stable or decreased after accelerated storage in all of the formulations, whilst odour ranking increased in most emulsions during accelerated storage, but not to the point of being offensive. These results suggest that some oxidation leading to fatty acid release had occurred during accelerated storage. Short chain fatty acids have offensive rancid odours (Olcott \& Mattill 1941) that were not observed here, so these molecules are unlikely to be present. The DATEM emulsifier was typically associated with the most acid $\mathrm{pH}$ and the strongest odour, most likely due to its high tartaric acid content (Riken Vitamin Co. 2013). The $\mathrm{pH}$ and odour were less affected by the choice of antioxidant than emulsifier, suggesting that all the antioxidants were doing a suitable job in minimising oxidation. Halving the amount of the antioxidant (e.g. T70), which is the most expensive ingredient, did not adversely affect the amount of oxidation as shown by free fatty acid analysis. Overall, the following products were considered less favourable for commercialisation: Lecithin, 204, 106, AP (product instability); DATEM (strong odour); SSL,CSL and PGPR (poor shelf life).

The Citrem, PGPR and lecithin emulsifiers were typically associated with less effective disease control for AMF, whilst formulations containing Citrem and SSL,CSL resulted in poorer disease control in the SBO experiment. Poor distribution of the active ingredient is the most likely explanation for poorer disease control with all these emulsifiers, apart from Citrem. The reason for the failure of Citrem is harder to explain, but is possibly due to some physical characteristics that were not measured in this study, or a chemical interaction between the active ingredient and the emulsifier.

The emulsifiers least damaging to plant tissue were PGE and CSL,SSL in the AMF trial and DATEM in the SBO trial, whilst antioxidants appeared to have little effect on leaf health. PGE and DATEM produce quite stable emulsions where the active lipid ingredient is evenly dispersed throughout the solution, thus avoiding concentrated pockets of oil that are more likely to damage plant tissue (Finger et al. 2002; Kordali et al. 2008; Ulukanli et al. 2014; Baysal-Gurel \& Miller 2015; Zhuang et al. 2015). Formulations containing PGE and DATEM were also associated with effective disease control hence less pathogen-induced chlorosis and necrosis. Use of the CSL,SSL emulsifier resulted in poorer disease control and, therefore, poorer leaf health in the SBO emulsifier trial compared with the AMF experiment. The two PGE emulsifiers from different manufacturing suppliers tested were indistinguishable.

Taking all factors into account, PGE was the best emulsifier and T70 the best antioxidant for both AMF and SBO emulsions. The extent of infection was higher following treatment with either the water control or the PGE/T70 combination in the SBO antioxidant experiment than in the SBO emulsifier experiment, and this was mostly likely due to much higher disease pressure observed in the antioxidant trial.

Commercialisation of a bio-fungicide requires taking into account all of these factors, as well as cost. Choice of the best products often requires achieving an acceptable trade-off between antagonistic factors. For example, stronger concentrations of formulation ingredients that result in better disease control efficacy can lead to phytotoxicity and higher cost. Only AMF and SBO formulations containing PGE and T70 satisfied all the conditions expected for commercial development i.e. they were stable, had an acceptable shelf life and inoffensive 
odour, were easy to use, exhibited good disease control, and mild phytotoxicity. In addition, halving the concentration of the most expensive ingredient, T70, had no adverse effects on product performance. Optimal formulation of these two bio-fungicides has been achieved, making them viable and attractive products for commercialisation.

\section{ACKNOWLEDGEMENTS}

We are extremely grateful to Andrea McDonald from Danisco New Zealand Limited, Sandra Murray from Hawkins Watts Limited New Zealand and Derek Horne from Dupont New Zealand for providing free samples for testing and product advice. Special thanks to Maryam Alavi for assistance with statistical analysis, to Mike Spiers and Dr Tony Reglinski for editorial advice, and to Dr Claire Hall for excellent business management. This research was funded by the PreSeed Accelerator Fund.

\section{REFERENCES}

Ah Chee A, Wurms KV, George M 2011. Control of powdery mildew (Sphaerotheca pannosa var. rosae) on rose (Rosa L. sp.) using anhydrous milk fat and soybean oil emulsions. New Zealand Plant Protection 64: 195-200.

Ah Chee A, George M, Alavi M, Wurms K 2018. Lipid-based bio-fungicides for control of powdery mildew in cucurbits. New Zealand Plant Protection 71: 262-271.

Baysal-Gurel F, Miller SA 2015. Management of powdery mildew in greenhouse tomato production with biorational products and fungicides. In: Paret ML, Vallad GE, Zhang $S$, Jones JB eds. IV International Symposium on Tomato Diseases. Acta Horticulturae. Pp. 179-183.

Finger SA, Wolf TK, Baudoin AB 2002. Effects of horticultural oils on the photosynthesis, fruit maturity, and crop yield of winegrapes. American Journal of Enology and Viticulture 53: 116-124.

Kordali S, Cakir A, Ozer H, Cakmakci R, Kesdek M, Mete E 2008. Antifungal, phytotoxic and insecticidal properties of essential oil isolated from Turkish Origanum acutidens and its three components, carvacrol, thymol and p-cymene. Bioresource Technology 99: 8788-8795.

Ministry for Primary Industries 2018. ACVM regsitration standard and guideline for the chemistry of veterinary medicines. www.mpi. govt.nz/exporting/agricultural-chemicalsand-vet-medicines/veterinary-medicines/ requirements/ (accessed 23 March 2018).

New Zealand Food Safety Authority 2006. ACVM regsitration standard and guideline for the chemistry of veterinary medicines. www.nzfsa.govt.nz/acvm/publications/ standards-guidelines/chem-pc.pdf (accessed 1 October 2006).

Moran RE, Deyton DE, Sams CE, Pless CD, Cummins JC 2003. Soybean oil as a summer spray for apple: European red mite control, net $\mathrm{CO}_{2}$ assimilation and phytotoxicity. HortScience 38: 234-238.

Olcott HS, Mattill HA 1941. Constituents of fats and oils affecting the development of rancidity. Chemical Reviews 29: 257-268.

Perrin DR, Perrin DD 1958. The determination of free fatty acids in milk. Journal of Dairy Research 25: 221-227.

Riken Vitamin Co. 2013. Kinds of food emulsifiers. www.rikenvitamin.com/foodingredients/ emulsifier/kind.html (accessed 16 March 2018).

Spencer DM 1977. Standardised methods for the evaluation of fungicides to control cucumber powdery mildew. In: McFarlane NR ed. Crop Protection Agents - Their Biological Evaluation. Academic Press, London. Pp. 455-464.

Ulukanli Z, Karaborklu S, Bozok F, Ates B, Erdogan S, Cenet M, Karaaslan MG 2014. Chemical composition, antimicrobial, insecticidal, phytotoxic and antioxidant activities of Mediterranean Pinus brutia and Pinus pinea resin essential oils. Chinese Journal of Natural Medicines 12: 901-910.

Wurms K, Ah Chee A, Elmer P, Agnew R, Wood P 2011. Developing new biologically-based 
products for control of botrytis bunch rot. Part 1: Developing a new natural product for mid-season botrytis control - NP2 moves closer to the market. Wine and Viticulture Journal 26: 64-72.

Wurms KV, Ah Chee A 2007. Fungicidal composition comprising anhydrous milk fat (AMF) and soybean oil for the treatment of powdery mildew, Patent No. NZ534007A. Horticulture \& Food Research Institute NZ.

Wurms KV, Ah Chee A 2011. Control of powdery mildew (Podosphaera leucotricha) on apple seedlings using anhydrous milk fat and soybean oil emulsions. New Zealand Plant Protection 64: 201-208.

Wurms KV, Hofland-Zijlstra JD 2015. Control of powdery mildew on glasshouse-grown roses and tomatoes in the Netherlands using anhydrous milk fat and soybean oil emulsions. New Zealand Plant Protection 68: 380-388.

Zhuang QG, Wang LH, Li MZ, Hou TP, Xie Y 2015. 'EnSpray 99' Mineral oils for white peach scale, Pseudaulacaspis pentagona and phytotoxicity to 'Hongyang' kiwifruit. In: Huang H, Zhang Q eds. VIII International Symposium on Kiwifruit. Acta Horticulturae. Pp. 363-369. 